\title{
Effects of stress typicality during spoken word recognition by native and nonnative speakers of English: Evidence from onset gating
}

\author{
JOANNE ARCIULI and LINDA CUPPLES \\ Macquarie University, Sydney, Australia
}

\begin{abstract}
Onset gating was used to investigate the effects of stress typicality during the processing of disyllabic nouns and verbs by 34 native and 36 nonnative speakers of English. We utilized 50-msec increments and included two conditions. In the silenced condition, only word onsets were presented (the participants had no information about the duration or stress pattern of the entire word). In the filtered condition, word onsets were presented with a low-pass filtered version of the remainder of the word (this type of filtering provides duration and stress information in the absence of phonemic information). The results demonstrated significant effects of stress typicality in both groups of speakers. Typically stressed trochaic nouns and iambic verbs exhibited advantaged processing, as compared with atypically stressed iambic nouns and trochaic verbs. There was no significant effect of presentation condition (silenced or filtered). The results are discussed in light of recent research in which the effects of lexical stress during spoken word recognition have been investigated.
\end{abstract}

The influence and use of prosody (also referred to as lexical stress at the single-word level) during spoken word recognition has received considerable attention in recent years (Arciuli \& Cupples, in press; Cooper, Cutler, \& Wales, 2002; Davis \& Kelly, 1997; Lindfield, Wingfield, \& Goodglass, 1999; Mattys \& Samuel, 2000; Wingfield, Lindfield, \& Goodglass, 2000). The research reported here is concerned with the effects of stress typicality (where typicality is determined on the basis of grammatical category) during spoken word recognition by native and nonnative speakers of English.

In English, most disyllabic words exhibit trochaic stress (MRC Database, Coltheart, 1981, and CELEX Database, Baayen, Piepenbrock, \& van Rijn, 1993); however, typical patterns of lexical stress vary across disyllabic nouns and verbs. Most disyllabic nouns exhibit trochaic stress, where primary stress is placed on the first syllable (e.g., patron), whereas most disyllabic verbs exhibit iambic stress, where primary stress is placed on the second syllable (e.g., prevent). These statistical distributions have been investigated by both Sereno (1986) and Kelly and Bock (1988). Sereno analyzed stress assignment in a sam-

The research reported here was based on a doctoral dissertation completed by J.A. under the supervision of L.C. at the Speech, Hearing and Language Research Centre (SHLRC). Some of these results were presented at the 15th ICPhS conference in Barcelona. We thank Richard Smith and Chris Callaghan for their help in preparing the sound files. We also thank Anne Cutler for discussions relating to the processing of lexical stress. Finally, we are grateful to Jay Rueckl, Louisa Slowiackzek, Arthur Wingfield, and Paul Luce for helpful comments on an earlier draft of the manuscript. Correspondence should be addressed to J. Arciuli, Department of Psychology, University College London, 26 Bedford Way, WC1HOAP (e-mail: j.arciuli@ucl.ac.uk). ple of 1,425 disyllabic nouns and 523 disyllabic verbs and found that $93 \%$ of the nouns exhibited trochaic stress, whereas $76 \%$ of the verbs exhibited iambic stress. Kelly and Bock reported similar results. They examined 3,000 disyllabic nouns, $94 \%$ of which exhibited a trochaic pattern of lexical stress, and 1,000 disyllabic verbs, $69 \%$ of which exhibited an iambic pattern. Further evidence for this correlation between lexical stress and grammatical category in English comes from homographs, such as permit and refuse. For such words, trochaic stress is typically assigned to the nominal meaning, and iambic stress to the verbal meaning (Sherman, 1975). A discussion of the origin of these differences in patterns of lexical stress across disyllabic nouns and verbs has been provided by Kelly (1992) and includes specific rhythmic biasing contexts created by word order and inflectional patterns in English. Regardless of how these stress differences might have come about, in the study reported here, we were interested in finding out whether native and nonnative speakers of English are sensitive to these statistical occurrences. Specifically, we wanted to know whether typically stressed trochaic nouns and iambic verbs would elicit advantaged processing, as compared with atypically stressed iambic nouns and trochaic verbs during onset-gating.

Interestingly, many early studies in which the processing of lexical stress (as opposed to stress typicality per se) was examined failed to show significant effects during spoken word recognition by native speakers of English (e.g., Bond \& Small, 1983; Cutler, 1986; Small, Simon, \& Goldberg, 1988). Moreover, in an early study, Cutler and Clifton (1984) also reported nonsignificant effects of stress typicality during spoken word recogni- 
tion. They used a grammatical judgment task in which native speakers of English heard disyllabic items in the context of "to ..." or "the ..." and had to decide whether what they heard was grammatical or not. The results suggested that native speakers do not show effects of stress typicality (i.e., the apple was no easier than the cigar and to await was no easier than to borrow).

More recently, Davis and Kelly (1997) used a different grammatical classification task to investigate the effects of stress typicality during spoken word recognition. In their task, native and nonnative speakers of English were presented with individual items and were asked to decide whether each one was a noun or a verb under speeded conditions. Davis and Kelly found no significant effects of stress typicality in native speakers but did find significant effects in nonnative speakers. They suggested that perhaps task difficulty and vocabulary differences might play a role in sensitivity to stress typicality. Specifically, their proposal was that a lack of vocabulary knowledge in nonnative speakers increases reliance on phonological cues to grammatical category. That is, in the absence of in-depth information about word meanings, participants are more likely to use typical patterns of lexical stress as a way of distinguishing between nouns and verbs (and thus, to have problems with atypically stressed words). Indeed, their nonnative speakers made more errors than did their native speakers during speeded grammatical classification and had lower levels of vocabulary knowledge for the words used in the experiment. However, Davis and Kelly did not provide results of statistical tests to demonstrate a relationship between overall error rate, vocabulary size, and the size of the stress typicality effect. They also concentrated on differences between speaker groups, rather than discussing the possibility of individual differences that might affect participants within each group.

In an earlier study, we expanded on the work of Davis and Kelly (1997) to investigate further the question of individual differences in sensitivity to stress typicality. We found that nonnative speakers and some native speakers of English showed significant effects of stress typicality when classifying spoken words according to grammatical class under speeded conditions (Arciuli \& Cupples, in press). Specifically, we found an overall effect of stress typicality for nonnative speakers, and a median split analysis revealed that native speakers with high error rates in the grammatical classification task showed significant effects of stress typicality. Furthermore, we provided a correlational analysis of native and nonnative speakers of English combined, which revealed a significant association between vocabulary size (measured independently) and the size of the stress typicality effect.

Like our recent study in which the speeded grammatical classification task was used, the results from another study conducted by Cooper et al. (2002) have provided support for the view that both native and nonnative speakers of English utilize information about lexical stress during spoken word recognition (although these investigators were not concerned with the effects of stress typicality per se). In their study, they included tasks that had not been used to examine the effects of lexical stress previously: cross-modal priming and forcedchoice identification. Cooper et al. emphasized the issue of task sensitivity, arguing that perhaps previous research had failed to detect stress effects because less sensitive tasks had been employed.

With this last point in mind we set out to find an appropriately sensitive task that might detect an overall effect of stress typicality (where typicality is determined on the basis of grammatical category) in both native and nonnative speakers of English. In our search, we came across the onset-gating paradigm. During onset gating, participants are presented with word segments of increasing duration and are asked to identify the word that is being presented (and are also often asked to provide a confidence rating for each of their responses). Following the seminal work of Grosjean (1980), increment size is usually consistent across gates and is normally somewhere between 20 and $100 \mathrm{msec}$. Thus, if the increment size is $50 \mathrm{msec}$, the initial gate will generally include the first $50 \mathrm{msec}$ of the word, the second gate will include the first $100 \mathrm{msec}$ of the word, and so on. Typically, the last gate corresponds to the entire stimulus.

Data collected from the onset-gating paradigm have commonly been reported in terms of the isolation point and the recognition point for each word. Some studies have also included an analysis of error rates. The isolation point is the point (in milliseconds) at which the participant correctly identified the word (and did not subsequently change his or her mind). The recognition point is the point (in milliseconds) at which the participant was highly confident about his or her response. For example, Tyler and Wessels (1983), analyzed confidence ratings at or above $80 \%$. Where a perfect confidence rating (i.e., $100 \%$ ) is used, the recognition point is referred to as the total acceptance point.

The task has been argued to measure on-line processing (Tyler \& Wessels, 1985) ${ }^{1}$ and has been used to examine the effects of context, word frequency, and coarticulation (for a review, see Grosjean, 1996). In addition, the paradigm has been used with a variety of populations, including children (Walley, 1988), people with aphasia (Tyler, 1992), and individuals with dyslexia (Griffiths \& Snowling, 2001).

More relevant to the topic of interest here, Lindfield et al. (1999) and Wingfield et al. (2000) used the onsetgating paradigm to investigate the use of prosody during spoken word recognition by native English speakers. In each of these studies, isolation points were examined for gated polysyllabic nouns (12 disyllables and 18 trisyllables) in three separate conditions. In all three conditions, each word was presented in 50-msec increments; however, the conditions varied according to the way in which the remainder of the word was presented: In the onsetonly condition, the remainder of the word was presented as silence; in the onset-plus-duration condition, the re- 
mainder of the word was filled with white noise; and finally, in the onset-plus-duration-plus-prosody condition, the remainder of the word was filtered with a low-pass cutoff of $325 \mathrm{~Hz}$ providing information about number of syllables and pattern of lexical stress in the absence of phonemic information. Results from both studies showed that participants were faster to recognize words in the onset-plus-duration-plus-prosody condition than in either of the other two conditions (there was no significant difference between the onset-only condition and the onset-plus-duration condition). That is, the provision of information pertaining to lexical stress appeared to facilitate word recognition.

Given that the onset-gating task has been used successfully to investigate a range of effects in spoken word recognition, we decided to use the technique in a further investigation of stress typicality effects in native and nonnative speakers. ${ }^{2}$ To our knowledge, this research is the first to employ the onset-gating paradigm for this purpose. We were particularly interested in whether we would be able to demonstrate an overall effect of stress typicality (where typicality is determined on the basis of grammatical category) in a group of native English speakers, something that previous research had failed to do.

Another aim was to explore further the hypothesis put forward by Lindfield et al. (1999) and Wingfield et al. (2000) that the provision of prosodic information for the entire stimulus (in the absence of segmental information) can facilitate spoken word recognition during onset gating. Where each of these previous studies included only native speakers of English, our research included both native and nonnative speakers. Since Lindfield et al. and Wingfield et al. (2000) found no significant difference between their onset-only condition and their onset-plusduration condition, we elected to reduce the number of presentation conditions in this study from three to two: the onset-only condition and the onset-plus-durationplus-prosody condition. For our purposes, these presentation conditions are hereafter referred to as the silenced condition and the filtered condition.

In designing this experiment, we had clear predictions in mind. First, we expected to find a significant main effect of stress typicality. That is, we expected that typically stressed trochaic nouns and iambic verbs would elicit advantaged processing over atypically stressed iambic nouns and trochaic verbs (in terms of isolation points, total acceptance points, and/or error rates). We hypothesized that the onset-gating paradigm would be sensitive enough to detect an overall effect of stress typicality in both native and nonnative speakers of English. However, on the basis of previous studies (Arciuli \& Cupples, 2003; Davis \& Kelly, 1997), we predicted that nonnative speakers might show a stronger effect than native speakers. Second, we expected to find an effect of presentation condition. Specifically, we hypothesized that the provision of prosodic information for the entire word in the filtered condition would facilitate processing, as compared with the silenced condition. Accord- ingly, if the provision of prosodic information can assist recognition during onset-gating, it seems likely that we would obtain a stronger effect of stress typicality in the filtered condition than in the silenced condition.

\section{METHOD}

\section{Participants}

A total of 34 native speakers of English and 36 nonnative speakers of English took part in the experiment. All were first-year undergraduate students with normal hearing and normal or correctedto-normal vision, who received course credit in return for their participation.

Nonnative speakers represented a range of different language backgrounds (mostly Chinese, Japanese, Vietnamese, and Korean, but also Italian, German, Hungarian, Croatian, Greek, Malay, Indian, Swedish, and Polish). All the nonnative speakers reported that they had spoken a language other than English until at least the age of 5 years.

\section{Materials}

Experimental items consisted of 40 disyllabic words: 20 nouns and 20 verbs. There were 10 nouns with typical trochaic stress (e.g., tension) and 10 nouns with atypical iambic stress (e.g., saloon). There were 10 verbs with typical iambic stress (e.g., forget) and 10 with atypical trochaic stress (e.g., follow). The complete set of experimental items is provided in Appendix A.

Typically and atypically stressed words were matched on initial phoneme (always a consonant) and did not differ significantly in terms of Francis and Kucera (1982) base frequency or CELEX spoken frequency (both $F \mathrm{~s}<1$ ). We also examined possible differences between typically and atypically stressed words according to a number of cohort variables that have been shown to affect spoken word recognition in previous studies: neighborhood size, average frequency of neighbors, onset density, and uniqueness point. In our analysis of neighborhood size, we searched CELEX for neighbors with the same stress pattern that differed in only one phoneme by means of substitution, addition, or deletion (the $\mathrm{Ph}+/-$ metric, as in Luce \& Pisoni, 1998). Typically stressed words had an average of 3.8 neighbors, whereas atypically stressed words had an average of 4.3 neighbors $(F<1)$. There was no significant difference between the average spoken frequency of neighbors across typically and atypically stressed words $[F(1,33)=3.41, p>.05]$. With regard to onset density (as in Vitevitch, 2002), 20\% of all phonological neighbors were initial-phoneme neighbors. Typically stressed words had an average onset density of 1.1 words, whereas atypically stressed words had an average onset density of 0.6 words $[F(1,35)=$ $1.82, p>.10]$. Our analysis of uniqueness points is provided in the Results section.

The stimuli were recorded using a female speaker of Australian English. The resulting files were normalized and presented in $44.1-\mathrm{kHz} 16$-bit DAT format with a linear fade from $t=0$ to $t=$ $50 \mathrm{msec}$ before the utterance. Following the method set out by Lindfield et al. (1999) and Wingfield et al. (2000), the files were prepared for presentation in the silenced (onset-only) and filtered (onset-plus-duration-plus-prosody) conditions. For each word in each condition, editing software was used to produce a sequence of files in which the gate size began at $100 \mathrm{msec}$ (because of a 50-msec linear fade before each utterance) and increased by increments of $50 \mathrm{msec}$ until the entire word had been presented. For the silenced condition, onsets were presented, with the remainder of the word being replaced by silence. For the filtered condition, files were prepared so that onsets were presented, with the remainder of the word being replaced by prosodic information (in the absence of segmental information). Prosodic information was supplied by passing the remainder of the word through a low-pass filter (cutoff of $325 \mathrm{~Hz}$ ). 
To avoid splicing artifacts, a cross-fade was included at each edit for each file in the filtered condition.

The average duration of typically and atypically stressed words was 613 and $572 \mathrm{msec}$, respectively $[F(1,38)=1.99, p>.10]$, and the average number of gates used in the presentation of typically and atypically stressed words was 12 and 11, respectively.

For each condition, the sequence of files for each word was recorded on a $\mathrm{CD}$, with a $6-\mathrm{sec}$ pause between each file. There were two random orders of presentation for each condition (the sequence of files for each word was, of course, presented in fixed order). The commencement of the sequence of files for each new word was signaled using an Australian male recording of the numbers 1-40 (followed by a 1 -sec pause).

\section{Procedure}

The experiment was conducted in a group setting (around 5 participants in each session) in a sound-proof room, with individual headphones provided for each participant. Sessions were around 60-min duration.

Each participant heard all 40 words in one of two random orders (R1 or R2) for one of two conditions (silenced vs. filtered). In the native speaker group, there were 16 participants in the silenced condition ( 8 were given R1, and 8 were given R2) and 18 participants in the filtered condition ( 10 were given $\mathrm{R} 1$, and 8 were given R2). In the nonnative speaker group, there were 19 participants in the silenced condition ( 9 were given R1, and 10 were given R2) and 17 participants in the filtered condition ( 9 were given $\mathrm{R} 1$, and 8 were given R2).

Each of the 40 words was presented as a sequence of files with increasing onsets (i.e., items were presented individually, not in a carrier phrase). After each presentation, the participants had to write down what they thought the word could be and how confident they were in their response (as a percentage, where $100 \%$ represented full confidence). The participants were under constant time pressure, in that the $\mathrm{CD}$ was continuously running. To assist the participants in keeping track of where they were up to, they were provided with a detailed response sheet listing the number of gates they should expect for each word.

\section{RESULTS}

As had been suggested by Grosjean (1996), response sheets were examined to determine the point (in milliseconds) at which each participant correctly identified the word and did not subsequently change his/her decision (isolation point). We also examined the point at which the participants indicated $100 \%$ confidence in their decision and did not subsequently change this confidence rating (total acceptance point). Finally, we examined the percentage of errors (where the participants failed to identify the word correctly after presentation of the final gate). Appendix B provides an example of two responses to the word cadet, presented in the filtered condition (one response from a native speaker and one from a nonnative speaker).

We found that order of randomization (R1 vs. R2) did not interact with any other variables in any of our analyses, so the results reported below do not include this variable. Participant analyses $\left(F_{1}\right)$ included presentation condition (silenced vs. filtered) as a between-subjects variable and stress typicality and grammatical status as repeated measures. Item analyses $\left(F_{2}\right)$ included presentation condition as a repeated measure and stress typicality and grammatical status as between-items variables. Number of gates was included as a covariate in all item analyses, because the provision of a detailed response sheet gave the participants prior information about the number of gates to be presented for each word.

\section{Isolation Points}

Some participants failed to identify a word correctly after the presentation of the final gate. We replaced these missing values $(7.5 \%$ of the data) with the duration of the word, rounded up to the nearest $50 \mathrm{msec}$. For example, a word of 564-msec duration would contain 11 gates. If such a word was not recognized after presentation of the final gate, the missing value would be replaced with a value of $600 \mathrm{msec}$.

Native speakers. The mean isolation points (and standard errors) for native speakers for each type of item in each presentation condition are presented in Table 1.

As was expected, our analysis of mean isolation points for the native speakers showed a main effect of stress typicality $\left[F_{1}(1,32)=136.78, p<.001 ; F_{2}(1,35)=\right.$ $8.12, p<.01]$. Typically stressed trochaic nouns and iambic verbs were recognized faster than atypically stressed iambic nouns and trochaic verbs. There were two effects that were significant by participants, but not by items. They included an effect of grammatical status $\left[F_{1}(1,32)=16.56, p<.001 ; F_{2}(1,35)=1.26, p>.10\right]$ and a three-way interaction involving grammatical status, condition, and stress typicality $\left[F_{1}(1,32)=4.46\right.$, $\left.p<.05 ; F_{2}<1\right]$. Interestingly, there was no significant main effect of presentation condition in the participant analysis or the item analysis $\left[F_{1}(1,32)=1.78, p>.10\right.$; $\left.F_{2}<1\right]$. That is, the participants responded in a similar manner to onsets presented with silence and to onsets

Table 1

Mean Isolation Points (in Milliseconds, With Standard Errors) as a Function of Presentation Condition, Stress Typicality, and Grammatical Category for Native Speakers

\begin{tabular}{|c|c|c|c|c|c|c|c|c|}
\hline \multirow{4}{*}{$\begin{array}{c}\text { Grammatical } \\
\text { Category }\end{array}$} & \multicolumn{8}{|c|}{ Presentation Condition } \\
\hline & \multicolumn{4}{|c|}{ Silenced } & \multicolumn{4}{|c|}{ Filtered } \\
\hline & \multicolumn{2}{|c|}{ Typical Stress } & \multicolumn{2}{|c|}{ Atypical Stress } & \multicolumn{2}{|c|}{ Typical Stress } & \multicolumn{2}{|c|}{ Atypical Stress } \\
\hline & $M$ & $S E$ & $M$ & $S E$ & $M$ & $S E$ & $M$ & $S E$ \\
\hline Nouns & 309.7 & 6.0 & 337.8 & 7.9 & 307.2 & 5.7 & 345.6 & $\overline{7.4}$ \\
\hline Verbs & 307.2 & 6.7 & 360.9 & 5.6 & 333.6 & 6.3 & 362.5 & 5.2 \\
\hline Overall & 308.4 & 5.4 & 349.4 & 4.8 & 320.4 & 5.1 & 354.0 & 4.5 \\
\hline
\end{tabular}


presented with prosodic information about the entire word. There were no other significant effects.

Nonnative speakers. The mean isolation points (and standard errors) for nonnative speakers for each type of item in each presentation condition are presented in Table 2.

Like those for the native speakers, the results from our nonnative speakers demonstrated a significant main effect of stress typicality $\left[F_{1}(1,34)=96.93, p<.01\right.$; $\left.F_{2}(1,35)=10.68, p<.005\right]$. Again, typically stressed trochaic nouns and iambic verbs were recognized faster than atypically stressed iambic nouns and trochaic verbs. The main effect of grammatical status was not significant in either analysis $\left[F_{1}(1,34)=1.41, p>.10 ; F_{2}<\right.$ $1]$. The interaction between stress typicality and grammatical status was significant by participants, but not by items $\left[F_{1}(1,34)=7.96, p<.01 ; F_{2}<1\right]$. There was no significant main effect of presentation condition in either analysis $\left[F_{1}(1,34)=1.01, p>.10 ; F_{2}<1\right]$ and no other significant effects.

\section{Error Rates}

Native speakers. The mean error rates (and standard errors) for the native speakers for each type of item in each presentation condition are presented in Table 3.

The first point to note about these data is that the native speakers of English made very few errors in this task once the final gate had been presented (and the whole word was available to them). In light of this ceiling effect, it is not surprising that our analysis of error rates for the native speakers did not show a main effect of stress typicality (both $F \mathrm{~s}<1$ ). Typically stressed trochaic nouns and iambic verbs did not elicit fewer errors than atypically stressed iambic nouns and trochaic verbs. There was also no main effect of grammatical status (both $F \mathrm{~s}<1$ ). Finally, although there was a small but significant effect of presentation condition in the participant analysis $\left[F_{1}(1,32)=6.61, p<.05\right]$, this effect did not reach significance in the item analysis $\left[F_{2}(1,35)=\right.$ $1.36, p>.10]$. There were no other significant effects.

Nonnative speakers. The mean error rates (and standard errors) for the nonnative speakers for each type of item in each presentation condition are presented in Table 4.

Unlike the native speaker group, the nonnative speakers made many more errors during the gating task and demonstrated a significant main effect of stress typicality $\left[F_{1}(1,34)=25.72, p<.001 ; F_{2}(1,35)=5.41, p<\right.$ $.05] .^{3}$ Typically stressed trochaic nouns and iambic verbs elicited fewer errors than did atypically stressed iambic nouns and trochaic verbs. Interestingly, on average, nouns elicited more errors than did verbs. This effect of grammatical status was significant in the participant analysis $\left[F_{1}(1,34)=15.22, p<.001\right]$ and was marginally significant in the item analysis $\left[F_{2}(1,35)=3.27\right.$, $p=.08]$. The interaction between stress typicality and grammatical status was significant by participants, but not by items $\left[F_{1}(1,34)=8.23, p<.01 ; F_{2}(1,35)=1.07\right.$, $p>.10]$. Finally, there was no significant main effect of presentation condition (both $F_{\mathrm{S}}<1$ ) and no other significant effects.

\section{Total Acceptance Points}

Many nonnative speakers often did not reach a total acceptance point (i.e., often their confidence ratings were less than $100 \%$ ) even after hearing the entire word. As a result of the large amount of missing data for the nonnative speakers, we are able to provide an analysis of total acceptance points only for the native speakers.

The mean total acceptance points (and standard errors) for the native speakers for each type of item in each presentation condition are presented in Table 5.

In line with the analysis of isolation points, an analysis of total acceptance points for the native speakers showed a significant effect of stress typicality. Typically stressed words elicited total acceptance points earlier than did atypically stressed words $\left[F_{1}(1,32)=12.75\right.$, $\left.p<.001 ; F_{2}(1,35)=8.20, p<.01\right]$. There were no other significant effects.

\section{Uniqueness Points}

As was stated earlier, our typically and atypically stressed words did not differ in terms of phonological neighborhood variables (i.e., number and average spoken frequency of neighbors and onset density). However, an analysis of uniqueness points is also important when the results of onset-gating experiments are interpreted, because it has been suggested that, during gating, a word is identified when it is "uniquely distinguishable from all other words in the language beginning with the same sound sequence" (Tyler \& Marslen-Wilson, 1982, p. 175). Thus, it is possible that our participants responded dif-

Table 2

Mean Isolation Points (in Milliseconds, With Standard Errors) as a Function of Presentation Condition, Stress Typicality, and Grammatical Category for Nonnative Speakers

\begin{tabular}{|c|c|c|c|c|c|c|c|c|}
\hline \multirow{4}{*}{$\begin{array}{c}\text { Grammatical } \\
\text { Category }\end{array}$} & \multicolumn{8}{|c|}{ Presentation Condition } \\
\hline & \multicolumn{4}{|c|}{ Silenced } & \multicolumn{4}{|c|}{ Filtered } \\
\hline & \multicolumn{2}{|c|}{ Typical Stress } & \multicolumn{2}{|c|}{ Atypical Stress } & \multicolumn{2}{|c|}{ Typical Stress } & \multicolumn{2}{|c|}{ Atypical Stress } \\
\hline & $M$ & $S E$ & $M$ & $S E$ & $M$ & $S E$ & $M$ & $S E$ \\
\hline Nouns & 353.2 & 13.7 & 414.7 & 16.2 & 371.8 & 14.4 & 429.1 & 17.1 \\
\hline Verbs & 351.3 & 13.9 & 397.1 & 10.5 & 382.9 & 14.7 & 401.5 & 11.1 \\
\hline Overall & 352.2 & 12.4 & 405.9 & 12.1 & 377.4 & 13.1 & 415.3 & 12.8 \\
\hline
\end{tabular}


Table 3

Mean Percentage Error Rates (With Standard Errors) as a Function of Presentation Condition, Stress Typicality, and Grammatical Category for Native Speakers

\begin{tabular}{|c|c|c|c|c|c|c|c|c|}
\hline \multirow{4}{*}{$\begin{array}{c}\text { Grammatical } \\
\text { Category } \\
\end{array}$} & \multicolumn{8}{|c|}{ Presentation Condition } \\
\hline & \multicolumn{4}{|c|}{ Silenced } & \multicolumn{4}{|c|}{ Filtered } \\
\hline & \multicolumn{2}{|c|}{ Typical Stress } & \multicolumn{2}{|c|}{ Atypical Stress } & \multicolumn{2}{|c|}{ Typical Stress } & \multicolumn{2}{|c|}{ Atypical Stress } \\
\hline & $M$ & $S E$ & $M$ & $S E$ & $M$ & $S E$ & $M$ & $S E$ \\
\hline Nouns & 1.9 & 2.3 & 2.5 & 4.0 & 0.0 & 2.2 & 0.0 & 3.7 \\
\hline Verbs & 0.6 & 2.7 & 1.9 & 2.6 & 0.6 & 2.5 & 0.0 & 2.5 \\
\hline Overall & 1.3 & 2.2 & 2.2 & 3.0 & 0.3 & 2.0 & 0.0 & 2.8 \\
\hline
\end{tabular}

ferently to typically and atypically stressed words because they have different uniqueness points.

We used the CELEX database to determine the uniqueness point of each of our items. We restricted our search to disyllabic words with the same stress pattern as the target item. For each item, we established which phoneme provided uniqueness. For example, for the typically stressed item relief, we established that the fifth phoneme, /f/, provided the point of separation from other words, such as release and relieve. We then divided this value by the total number of phonemes in the word. So, for relief, we divided 5 by 5 , and the resulting uniqueness value was 1 . For success, the uniqueness value was 0.83 (the fifth phoneme provided separation from other words, such as succinct). For some items, the uniqueness value was greater than 1. For example, region is not unique, because of regent. For this item, we divided the total number of phonemes in regent (5) by the total number of items in region (4). The resulting value was 1.25 .4

Using this method, we obtained the average uniqueness value for typically stressed words and atypically stressed words ( 0.83 and 0.85 , respectively). A one-way analysis of variance revealed no significant difference between these values $(F<1)$. Although uniqueness points cannot be used to explain our stress typicality effects, we wondered whether there might be a significant correlation between uniqueness points and isolation points (which would provide some support for the theory that word-initial input drives spoken word recognition). Interestingly, averaged across native and nonnative speakers and controlling for number of gates, the data did show a significant positive relationship between these variables $(r=.43, p<.05)$. When we ran the same correlational analysis with number of phonological neighbors, rather than uniqueness points, we did not find a significant relationship ( $r=.02, p>.50)$. Similarly, there was no significant relationship between average spoken frequency of neighbors and isolation points $(r=$ $.10, p>.50)$ or between onset density and isolation points $(r=-.05, p>.50)$.

\section{DISCUSSION}

In line with our expectations, both native and nonnative speakers of English exhibited overall effects of stress typicality during onset gating. Specifically, the participants needed less acoustic information to identify typically stressed trochaic nouns and iambic verbs than atypically stressed iambic nouns and trochaic verbs (as is illustrated in the isolation point data). Advantaged processing for typically stressed words was also demonstrated in the error rates for nonnative speakers and in the total acceptance point data for native speakers. It appears that listeners are sensitive to statistical occurrences in English, whereby nouns with trochaic stress and verbs with iambic stress are encountered more often (and are, thus, easier to recognize) than nouns with iambic stress and verbs with trochaic stress.

One of the most salient findings from this experiment is that both native and nonnative speaker groups showed significant main effects of stress typicality in their isolation point data. This pattern of results contrasts with earlier studies by Arciuli and Cupples (in press) and Davis and Kelly (1997) that revealed overall effects of stress typicality in nonnative speakers, with an absence of overall effects in native speakers. Importantly, in these previous studies, the participants were always presented with an entire spoken word before being asked to make

Table 4

Mean Percentage Error Rates (With Standard Errors) as a Function of Presentation Condition, Stress Typicality, and Grammatical Category for Nonnative Speakers

\begin{tabular}{|c|c|c|c|c|c|c|c|c|}
\hline \multirow{4}{*}{$\begin{array}{c}\text { Grammatical } \\
\text { Category }\end{array}$} & \multicolumn{8}{|c|}{ Presentation Condition } \\
\hline & \multicolumn{4}{|c|}{ Silenced } & \multicolumn{4}{|c|}{ Filtered } \\
\hline & \multicolumn{2}{|c|}{ Typical Stress } & \multicolumn{2}{|c|}{ Atypical Stress } & \multicolumn{2}{|c|}{ Typical Stress } & \multicolumn{2}{|c|}{ Atypical Stress } \\
\hline & $M$ & $S E$ & $M$ & $S E$ & $M$ & $\overline{S E}$ & $M$ & $S E$ \\
\hline Nouns & 9.5 & 2.1 & 25.3 & 3.6 & 12.4 & 2.2 & 22.9 & 3.8 \\
\hline Verbs & 9.5 & 2.4 & 12.1 & 2.4 & 6.5 & 2.6 & 12.4 & 2.5 \\
\hline Overall & 9.5 & 2.0 & 18.7 & 2.8 & 9.4 & 2.1 & 17.6 & 2.9 \\
\hline
\end{tabular}


Table 5

Mean Total Acceptance Points (in Milliseconds, With Standard Errors) as a Function of Presentation Condition, Stress Typicality, and Grammatical Category for Native Speakers

\begin{tabular}{|c|c|c|c|c|c|c|c|c|}
\hline \multirow{4}{*}{$\begin{array}{c}\text { Grammatical } \\
\text { Category } \\
\end{array}$} & \multicolumn{8}{|c|}{ Presentation Condition } \\
\hline & \multicolumn{4}{|c|}{ Silenced } & \multicolumn{4}{|c|}{ Filtered } \\
\hline & \multicolumn{2}{|c|}{ Typical Stress } & \multicolumn{2}{|c|}{ Atypical Stress } & \multicolumn{2}{|c|}{ Typical Stress } & \multicolumn{2}{|c|}{ Atypical Stress } \\
\hline & $M$ & $S E$ & $M$ & $S E$ & $M$ & $S E$ & $M$ & $S E$ \\
\hline Nouns & 437.2 & 12.4 & 465.3 & 13.2 & 426.7 & 11.7 & 466.4 & 12.4 \\
\hline Verbs & 446.6 & 15.4 & 458.8 & 10.4 & 424.4 & 14.5 & 443.6 & 9.8 \\
\hline Overall & 441.9 & 11.3 & 462.0 & 9.7 & 425.6 & 10.7 & 455.0 & 9.2 \\
\hline
\end{tabular}

a response. By contrast, in the onset-gating paradigm, listeners respond on the basis of only partial information about spoken word stimuli. To this extent, onset gating seems to tap more clearly into the perceptual and cognitive processes that listeners engage in during the course of identifying words. In line with this view, error rates (which occur after presentation of the entire stimulus) did show the interaction predicted on the basis of previous research; that is, a significant processing advantage for typically stressed words emerged for nonnative speakers, but not for native speakers. Furthermore, as in previous research, this interaction was associated with overall error rate, to the extent that the native speakers made very few errors once the entire spoken word was available to them. Although it is clear that more research is needed before strong conclusions can be drawn concerning similarities and/or differences in sensitivity to stress typicality by native versus nonnative speakers of English, the results reported here suggest that future research should distinguish between tasks that tap into different aspects of the word recognition process. Future research might also look at stress typicality effects across native and nonnative speakers after the introduction of noise masking to keep native speakers off ceiling levels.

In relation to the effects of lexical stress within native speakers, the results reported here are in line with a growing body of evidence demonstrating that such effects do emerge during spoken word recognition. Some of the reasons that previous studies have failed to find such effects could be related to task selection (as has been argued by Cooper et al., 2002) or perhaps to a lack of consideration of individual differences within native speakers (as has been argued by Arciuli \& Cupples, in press). What this study clearly indicates is that along with the cross-modal priming and forced-choice identification tasks utilized by Cooper et al., the onset-gating task appears to be an appropriately sensitive task for use in the investigation of lexical stress in native speakers of English.

It is noteworthy that our findings for verbs (iambic stress easier than trochaic) appear, on the surface, to be inconsistent with some recent research reported by Mattys and Samuel (2000). They used a phoneme-monitoring task to examine the hypothesis that English disyllables with trochaic stress are easier to process overall than those with iambic stress. In apparent contrast to the findings reported here, their results confirmed this hypothe- sis for a group of native speakers. However, because Mattys and Samuel did not manipulate grammatical category as part of their experimental design, they did not include equal numbers of matched disyllabic nouns and verbs (with trochaic and iambic stress). Hence, it is not possible to compare the two sets of results directly.

As was outlined in the introduction, we also predicted that presentation condition (silenced vs. filtered) would have a significant influence on spoken word recognition during onset gating (exhibited as a main effect of presentation condition and as an interaction between stress typicality and presentation condition). The reason for this prediction, based on previous studies by Lindfield et al. (1999) and Wingfield et al. (2000), was that the provision of duration and stress information (in the filtered condition) should reduce the number of potential word candidates and, thereby, facilitate processing (as compared with the silenced condition, where there would be no facilitation). Interestingly, our results revealed no influence of presentation condition. Of course, there are several important methodological differences between our study and these previous studies that might account for the different patterns of results.

Most obviously, the different stimuli and procedures used in the studies make direct comparison difficult. Whereas we included 40 disyllabic words (20 nouns and 20 verbs), Lindfield et al. (1999) and Wingfield et al. (2000) used 12 disyllabic words and 18 trisyllabic words (all nouns). It would be interesting to know whether the data collected by Lindfield et al. and Wingfield et al. (2000) showed the same effects of presentation condition across disyllabic and trisyllabic words. The procedures used in the present study also differed from those used in the previous studies. In particular, the participants in the previous studies responded verbally after each gate and were under no time pressure. ${ }^{5} \mathrm{By}$ contrast, the participants in the present study provided written responses and were under constant and reliable time pressure, since files were assembled in sequence and presented via a continuously running $C D$.

In sum, there are several possible reasons why our results might differ from the results of earlier studies in regard to the contrast between silenced and filtered presentation conditions. Although a definitive answer cannot be given here, the question provides an interesting avenue for further investigation, especially in light of the implications for theories of spoken word recogni- 
tion. Specifically, some theorists have suggested that identification of a spoken word relies primarily on wordinitial information, as opposed to information contained in the whole word.

In her discussion of the potential importance of wordinitial information during spoken word recognition, Walley (1988) noted that word-initial information reaches the listener first (especially pertinent in view of the transience of the speech waveform) and that word-initial information is more resistant to change by phonological processes. Indeed, studies in which a variety of paradigms were used, including noise replacement/addition and gating, have shown that word-initial information facilitates spoken word recognition more than does word-final information (e.g., Cole \& Jakimik, 1980; Nooteboom, 1981; Salasoo \& Pisoni, 1985; Walley, 1988; Wingfield, Goodglass, \& Lindfield, 1997).

In line with a strong version of the view that wordinitial information drives spoken word recognition, the provision of extra information (such as the duration and prosody information provided in the filtered condition) should have little impact on the recognition process. Indeed, in the study reported here, the participants heard the same amount of word-initial phonemic information in both conditions (silenced and filtered). Moreover, the results demonstrated a significant correlation between isolation points and uniqueness points. This finding is particularly relevant considering that some researchers describe spoken word recognition as a process whereby the cohort of competitor words (words sharing one or more consecutive phonemes with the target-compare create and creole) is gradually reduced until a single word (the target) remains (e.g., Marslen-Wilson \& Welsh, 1978). According to this kind of theoretical perspective, it would be expected that the uniqueness point (or the point at which a word diverges from other words with phonologically similar beginnings) should predict recognition times (see, e.g., Radeau, Morais, Mousty, \& Bertelson, 2000).

A reliance on word-initial information during spoken word recognition could be used to explain both the absence of a main effect of presentation condition and the absence of an interaction between presentation condition and stress typicality in the present study. The fact remains, however, that previous studies have shown an influence of presentation condition. What we are suggesting here is that, perhaps, reliance on word-initial information might be increased when any (or some combination) of the following conditions are present: (1) the inclusion of shorter words as experimental stimuli (disyllabic vs. trisyllabic words), (2) the inclusion of a list of stimuli that contains words of the same length, or (3) placing participants under time pressure to respond. All three conditions were present in the experiment reported here.

Besides significant stress typicality effects in our analyses of isolation points, error rates, and total acceptance points, there were no other effects (i.e., grammatical status or presentation condition) that reached conventional levels of significance, in both participant and item analyses. However, our analysis of error rates for nonnative speakers showed an effect of grammatical category that was significant by participants and marginally significant by items. This finding indicated that disyllabic verbs elicited fewer errors than did disyllabic nouns. Although an in-depth analysis of noun and verb processing by nonnative speakers was not a primary focus of the study, we have noted with interest that a verb advantage has been found in other studies of processing by nonnative speakers. For example, Yeni-Komshian, Robbins, and Flege (2001) included monosyllabic nouns and verbs and found a similar pattern in their assessment of 192 adult nonnative speakers (Korean-English bilinguals). In pronunciation and grammaticality judgment tasks (utilizing target words embedded in sentences), their participants were more accurate in their responses to verbs than to nouns. They provided a discussion of the hypothesis that in some languages (e.g., Korean and Mandarin Chinese), children exhibit a verb bias in early vocabulary. Interestingly, of the 36 nonnative speakers included in the present study, around half were from Asian-speaking backgrounds (including Chinese, Japanese, Vietnamese, and Korean participants). So, although the present study provides some evidence for a verb bias in the processing of disyllabic words by nonnative speakers of English, further investigation is required. Such investigations should include both monosyllabic and polysyllabic words and could also focus on the role of different language backgrounds.

In conclusion, as far as we are aware, this study is the first to investigate effects of stress typicality across native and nonnative speakers of English, using the onset-gating paradigm. The results have demonstrated that typically stressed trochaic nouns and iambic verbs elicit advantaged processing, as compared with atypically stressed iambic nouns and trochaic verbs, in both speaker groups. Whereas both native and nonnative speakers showed a significant effect of stress typicality in terms of isolation points, only nonnative speakers showed an overall significant effect in error rates. (Unfortunately, total acceptance points could not be compared across groups, because the large number of missing data points for nonnative speakers prevented an analysis of those data.) Importantly, the stress typicality effects reported in this study cannot be attributed to differences in frequency, acoustic duration, phonological neighborhood variables (neighborhood size, average frequency of neighbors, or onset density), or uniqueness points across typically and atypically stressed words. Moreover, they were equally strong irrespective of whether the listeners were provided with acoustic information about word beginnings only (silenced condition) or with acoustic information about word beginnings plus additional information about word duration and stress (filtered condition). We conclude that listeners are sensitive to statistical occurrences in English whereby nouns with trochaic stress and verbs with iambic stress are more commonly encountered and, thus, easier to recognize than nouns with iambic stress and verbs with trochaic stress. 


\section{REFERENCES}

ArCiUli, J., \& CuPPles, L. (in press). Effects of stress typicality during speeded grammatical classification. Language \& Speech.

BaAyen, R. H., PiePenbrock, R., \& van RiJn, H. (1993). The CELEX lexical database [CD-ROM]. Philadelphia: University of Pennsylvania, Linguistic Data Consortium.

Bond, Z. S., \& SMAll, L. H. (1983). Voicing, vowel, and stress mispronunciations in continuous speech. Perception \& Psychophysics, 34, 470-474.

Cole, R., \& JAKIMIK, J. (1980). How are syllables used to recognize words? Journal of the Acoustical Society of America, 67, 965-970.

Coltheart, M. (1981). The MRC psycholinguistic database. Quarterly Journal of Experimental Psychology, 33A, 497-505.

Cooper, N., Cutler, A., \& Wales, R. (2002). Constraints of lexical stress on lexical access in English:Evidence from native and non-native listeners. Language \& Speech, 45, 207-228.

Cutler, A. (1986). Forbear is a homophone: Lexical prosody does not constrain lexical access. Language \& Speech, 29, 201-220.

Cutler, A., \& Clifton, C. (1984). The use of prosodic information in word recognition. In H. Bouma \& D. G. Bouwhuis (Eds.), Attention and performance X: Control of language processes (pp. 183-196). Hillsdale, NJ: Erlbaum.

Davis, S. M., \& Kelly, M. H. (1997). Knowledge of the English noun-verb stress difference by native and nonnative speakers. Journal of Memory \& Language, 36, 445-460.

FRANCIS, W. N., \& KUČERA, H. (1982). Frequency analysis of English usage: Lexicon and grammar. Boston: Houghton-Mifflin.

GRIFFITHS, Y., \& SNOWLING, M. (2001). Auditory word identification and phonological skills in dyslexic and average readers. Applied Psycholinguistics, 22, 419-439.

Grosjean, F. (1980). Spoken word recognition processes and the gating paradigm. Perception \& Psychophysics, 28, 267-283.

Grosjean, F. (1996). Gating. Language \& Cognitive Processes, 11, 597-604.

KELLY, M. H. (1992). Using sound to solve syntactic problems: The role of phonology in grammatical category assignments. Psychological Review, 99, 349-364.

Kelly, M. H., \& Bock, J. K. (1988). Stress in time. Journal of Experimental Psychology: Human Perception \& Performance, 14, 389-403.

LindField, R., WingField, A., \& Goodglass, H. (1999). The contribution of prosody to spoken word recognition. Applied Psycholinguistics, 20, 397-407.

LuCE, P., \& Pisoni, D. (1998). Recognising spoken words: The neighbourhood activation model. Ear \& Hearing, 19, 1-36.

Marslen-Wilson, W., \& Welsh, A. (1978). Processing interactions and lexical access during word recognition in continuous speech. Cognitive Psychology, 10, 29-63.

MATTYS, S., \& SAMUEL, A. (2000). Implications of stress-pattern differences in spoken word recognition. Journal of Memory \& Language, 42, 571-596.

Noотевоом, S. (1981). Lexical retrieval from fragments of spoken words: Beginnings versus endings. Journal of Phonetics, 9, 407-424.

Radeau, M., Morais, J., Mousty, P., \& Bertelson, P. (2000). The effect of speaking rate on the role of the uniqueness point in spoken word recognition. Journal of Memory \& Language, 42, 406-422.

SAlAsoo, A., \& PisOnI, D. (1985). Interaction of knowledge sources in spoken word identification. Journal of Memory \& Language, 24, 210-231.

SERENO, J. A. (1986). Stress pattern differentiation of form class in English [Abstract]. Journal of the Acoustical Society of America, 79, S36.
SHERMAN, D. (1975). Noun-verb stress alternation: An example of lexical diffusion of sound change in English. Linguistics, 159, 43-71.

Small, L. H., Simon, S. D., \& GoldberG, J. S. (1988). Lexical stress and lexical access: Homographs versus nonhomographs. Perception \& Psychophysics, 44, 272-280.

TYLER, L. K. (1992). Spoken language comprehension: An experimental approach to disordered and normal processing. Cambridge, MA: MIT Press.

TYLER, L. K., \& MARSLEN-Wilson, W. (1982). Speech comprehension processes. In J. Mehler, E. C. T. Walker, \& M. Garrett (Eds.), Perspectives on mental representation: Experimental and theoretical studies of cognitive processes and capacities (pp. 169-184). Hillsdale, NJ: Erlbaum.

Tyler, L. K., \& Wessels, J. (1983). Quantifying contextual contributions to word-recognition processes. Perception \& Psychophysics, 34, 409-420.

Tyler, L. K., \& WeSSELS, J. (1985). Is gating an on-line task? Evidence from naming latency data. Perception \& Psychophysics, 38, 217-222.

Vite Vitch, M. (2002). Influence of onset density on spoken word recognition. Journal of Experimental Psychology: Human Perception \& Performance, 28, 270-278.

WALley, A. (1988). Spoken word recognition by young children and adults. Cognitive Development, 3, 137-165.

WingField, A., Goodglass, H., \& LindFIELD, K. (1997). Word recognition from acoustic onsets and acoustic offsets: Effects of cohort size and syllabic stress. Applied Psycholinguistics, 18, 85-100.

WingField, A., LiNDFIELD, K., \& GoOdGLASS, H. (2000). Effects of age and hearing sensitivity on the use of prosodic information in spoken word recognition. Journal of Speech, Language, \& Hearing Research, 43, 915-925.

Yeni-Komshian, G., Robbins, M., \& Flege, J. (2001). Effects of word class differences on L2 pronunciation accuracy. Applied Psycholinguistics, 22, 283-299.

\section{NOTES}

1. Although we believe that the onset-gating task measures on-line word recognition, we must acknowledge that this assumption has been a matter of some debate (see Grosjean, 1996).

2. In fact, the use of degraded stimuli in the onset-gating task might be particularly appropriate for examining typicality effects. As a reviewer pointed out, degraded stimuli encourage the use of frequencybased biases (in this case, a bias toward trochaic stress in disyllabic nouns and iambic stress in disyllabic verbs).

3 . To confirm statistically that native speakers and nonnative speakers showed different effects of stress typicality in terms of error rates, an analysis of variance was conducted incorporating the factors of group (native vs. nonnative speaker), stress typicality (typical vs. atypical), grammatical category (noun vs. verb), and presentation condition (silenced vs. filtered). As was expected, the interaction between group and stress typicality was significant $\left[F_{1}(1,66)=21.35, p<.001\right.$; $\left.F_{2}(1,35)=5.14, p<.05\right]$.

4. Including disyllabic words with different stress patterns is not likely to change uniqueness values. For example, for the word tension a search of same stress words returns a uniqueness point of 1.2 because of tensions. A search of words with different stress patterns returns words with the same onsets, such as tenpin (both syllables are equally stressed in this word). However, including these in the uniqueness calculation still produces a value of 1.2.

5. We are grateful to Arthur Wingfield for confirming this difference in procedure. 
APPENDIX A

Stimuli

\begin{tabular}{ccccc}
\hline \multicolumn{2}{c}{ Nouns } & & \multicolumn{2}{c}{ Verbs } \\
\cline { 2 - 2 } \cline { 5 - 5 } Typical (Trochaic) & Atypical (Iambic) & & Typical (Iambic) & Atypical (Trochaic) \\
\hline tension & technique & & create & carry \\
symbol & success & & forget & follow \\
dinner & degree & & refer & realize \\
region & relief & & deny & differ \\
danger & device & & prevent & publish \\
solvent & saloon & & deprive & deafen \\
demon & debris & & comply & conquer \\
kernel & cadet & & consume & cancel \\
patron & platoon & & dissolve & dazzle \\
leisure & lapel & suppress & soften \\
\hline
\end{tabular}

APPENDIX B

Example Responses to the Word Cadet Presented in the Filtered Condition

\begin{tabular}{|c|c|c|c|}
\hline \multicolumn{2}{|c|}{ Native Speaker } & \multicolumn{2}{|c|}{ Nonnative Speaker } \\
\hline Response & Confidence (\%) & Response & Confidence (\%) \\
\hline convey & 10 & couldn't & 0 \\
\hline contain & 5 & couldn't & 0 \\
\hline cadet & 10 & kitten & 0 \\
\hline cadet & 15 & kitten & 0 \\
\hline cadet & 50 & Quebec & 10 \\
\hline cadet & 80 & Quebec & 10 \\
\hline cadet & 100 & Quebec & 20 \\
\hline cadet & 100 & Quebec & 0 \\
\hline cadet & 100 & Quebec & 0 \\
\hline cadet & 100 & Quebec & 0 \\
\hline
\end{tabular}

Note-There were 10 gates: $100 \mathrm{msec}, 150 \mathrm{msec}, 200 \mathrm{msec}$, and so on.

(Manuscript received April 1, 2003;

revision accepted for publication July 15, 2003.) 